\title{
GIS-based prediction of groundwater fluoride contamination zones in Telangana, India
}

\author{
S Kiran Kumar Reddy ${ }^{1}$, Dinesh Kumar Sahadevan ${ }^{1}$, Harish Gupta ${ }^{2, *}$ (® \\ and DONTIREDDY VENKAT REDDY ${ }^{1}$ \\ ${ }^{1}$ CSIR-National Geophysical Research Institute, Hyderabad 500 00\%, India. \\ ${ }^{2}$ Osmania University, Hyderabad, India. \\ *Corresponding author.e-mail: harishgupta78@gmail.com
}

MS received 8 May 2018; revised 27 July 2018; accepted 30 August 2018; published online 13 May 2019

Groundwater is the only perennial water resource available to rural communities, especially in semi-arid regions. This study aims to provide an overview of fluoride-contaminated groundwater in the Telangana, India, by predicting potentially affected areas. The prevalence of endemic fluorosis in different parts of Telangana has been widely reported. Therefore, it is necessary to demarcate the fluoride-affected areas to adopt the remedial measures. In this context, the available information on related environmental variables such as geological settings, hydro-morphological inputs, climatic information and soil properties have been integrated as thematic layers in an ArcGIS environment. The thematic layers and their features were assigned with suitable weights, which were normalised using the analytic hierarchy process to obtain final ranks and the weighted overlay analysis method was carried out to delineate the potential fluoride contamination (PFC) zones. The entire state was classified into four broad categories, i.e., very high $(17.6 \%)$, high $(15.8 \%)$, medium $(32.7 \%)$ and low $(33.9 \%)$, in terms of groundwater fluoride enrichment. A comparison of the output map and the reported data indicates that the PFC zone model could explain $68.7 \%$ of fluoride variation. This study is the first such attempt to offer a regional-scale $\mathrm{PFC}$ zone for an entire state and offers a first-hand insight into the severity of fluoride contamination.

Keywords. Geographic information system; AHP technique; contamination; fluoride; groundwater; India.

\section{Introduction}

Fluoride $\left(\mathrm{F}^{-}\right)$occurs as a natural secondary constituent $(0.01-10 \mathrm{mg} / \mathrm{l})$ in groundwater. The acceptable limit of fluoride in drinking water according to the Bureau of Indian Standards recommendation is $1 \mathrm{mg} / \mathrm{l}$; however, in the absence of an alternate source, the permitted limit is $1.5 \mathrm{mg} / \mathrm{l}$ (BIS 2012). The WHO's prescribed guideline value for fluoride is $1.5 \mathrm{mg} / \mathrm{l}$ (WHO 2010) and a presence in excess makes it as one of the major geogenic contaminants. There are several geographical belts across the world having rocks and soils with high fluoride content, and India lies in one such belt (Mollert 1993). Besides, out of 85 million tons of fluoride deposits on the Earth's crust, about 12 million tons are found in India (Teotia and Teotia 1984). Therefore, fluoride is the most widespread geogenic contaminant (the second being arsenic) in India. 
American and European dentists have started linking dental staining and fluoridation by the start of the 20th century. However, the first case of fluorosis in India was reported in the year 1937 by Shortt et al. (1937) in the erstwhile Guntur district of Andhra Pradesh. By 1950, along with Andhra Pradesh, three other states (i.e., Punjab, Tamil Nadu and Uttar Pradesh) reported the presence of endemic fluorosis. At present, 201 districts of 20 (out of 29) Indian states are reported to be affected by fluoride (Chakraborti et al. 2016). This situation is particularly worrisome as $85 \%$ of the drinking water supply in India is derived from groundwater sources (World Bank 2010). It is suggested that in India, $>80 \%$ of rural and $50 \%$ of the urban population depend on groundwater for their domestic requirements (Mall et al. 2006). It is estimated that about $56 \%$ of the rural households secure their potable water from tube wells and $14 \%$ from dug wells (NSSO 2006). Therefore, the skeletal and dental health of about 66 million people $(5 \%$ of the Indian population) is at risk due to a high level of fluoride exposure (Planning Commission 2002). Starting from 1937 and particularly during the last few decades, numerous groundwater studies were carried out to measure the concentrations, to map the geographical extent of endemic regions and for delineating the factors regulating fluoride contamination across the country (Chakraborti et al. 2016). Handa (1975), Susheela (1999), Saxena and Ahmed (2003) and Jacks et al. (2005) have taken up regional scale studies on groundwater fluoride contamination, in India. Mukherjee and Singh (2018) have reviewed the various studies on fluoride in groundwater and discussed the contaminant mechanisms. In the Andhra-Telangana region, major studies on fluoride contamination include Kumar et al. (1991), Rao et al. (1993), Rao and Devadas (2003), Sujatha (2003), Sujatha and Reddy (2003), Rao (2006, 2009), Mondal et al. (2009), Reddy et al. (2010a,b), Brindha et al. (2011), Narsimha and Sudarshan (2016, 2017), etc.

Telangana with an area of $112,077 \mathrm{~km}^{2}$ is the 12th largest state of India. According to the recent findings of the Central Ground Water Board, India (CGWB 2015), about 1174 settlements across the Telangana are affected by endemic fluorosis. During the past three decades, fluoride ${ }^{-}$contamination recorded mostly from the areas underlain by granitic and gneissic complexes, i.e., Nalgonda (Rao et al. 1993; Mondal et al.
2009; Reddy et al. 2010a, b; Brindha et al. 2011; Machender et al. 2014), RangaReddy (Kumar et al. 1991; Sujatha 2003; Sreedevi et al. 2006), Karimnagar (Sudarshan 2015), Warangal (Radhika and Praveen 2012; Satyanarayana et al. 2017), Medak (Narsimha and Sudarshan 2017) and Adilabad (Narsimha and Sudarshan 2016). Despite numerous efforts, the areas taken up for fluoride contamination studies add to $22 \%$ of the total geographical area of the state. Nalgonda district which is one of the most severely fluorosis-affected areas is covered extensively (over 2000 samples from the $14,200 \mathrm{~km}^{2}$ area; Rao et al. 1993) followed by Medak (200 samples from the $9700 \mathrm{~km}^{2}$ area; Narsimha and Sudarshan 2017). The rest of the districts are sporadically sampled; therefore, information on the extent of fluoride in the groundwater remains elusive. Government agencies, such as CGWB, maintain 736 wells across the state to monitor groundwater depth and water quality (CGWB 2015). However, CGWB provides block-wise normalised data for the presence of fluoride, thus making it difficult to delineate the true extent of affected areas and to evaluate the controlling factors. Due to the lack of site-specific data and the disproportional distribution of measured sites, the representativeness of existing data is debatable. Besides, it might be a mammoth task to cover the entire state through conventional sampling.

Remote sensing (RS) and GIS have become popular among the scientific community due to their time and cost-effectiveness, particularly in regional-scale studies. Having started with applications in groundwater exploration, assessment, monitoring and recharge, now these techniques are even being used for predicting groundwater contamination (Babiker et al. 2005; Rahman 2008; Chitsazan and Akhtari 2009; Pathak et al. 2009; Saidi et al. 2010). More recently Thapa et al. (2017) have demonstrated the applicability of the geospatial modelling technique in the delineating the fluoride-contaminated zones. Due to the lack of adequate data on measured fluoride concentrations and in the wake of advancement in the applicability of GIS in delineating the fluoridecontaminated zones, this study aims to provide a regional scale probability map that indicates the risk of fluoride contamination in groundwater. The map of potential fluoride contamination (PFC) zones of Telangana is developed by employing the spatial distribution of various environmental variables. 


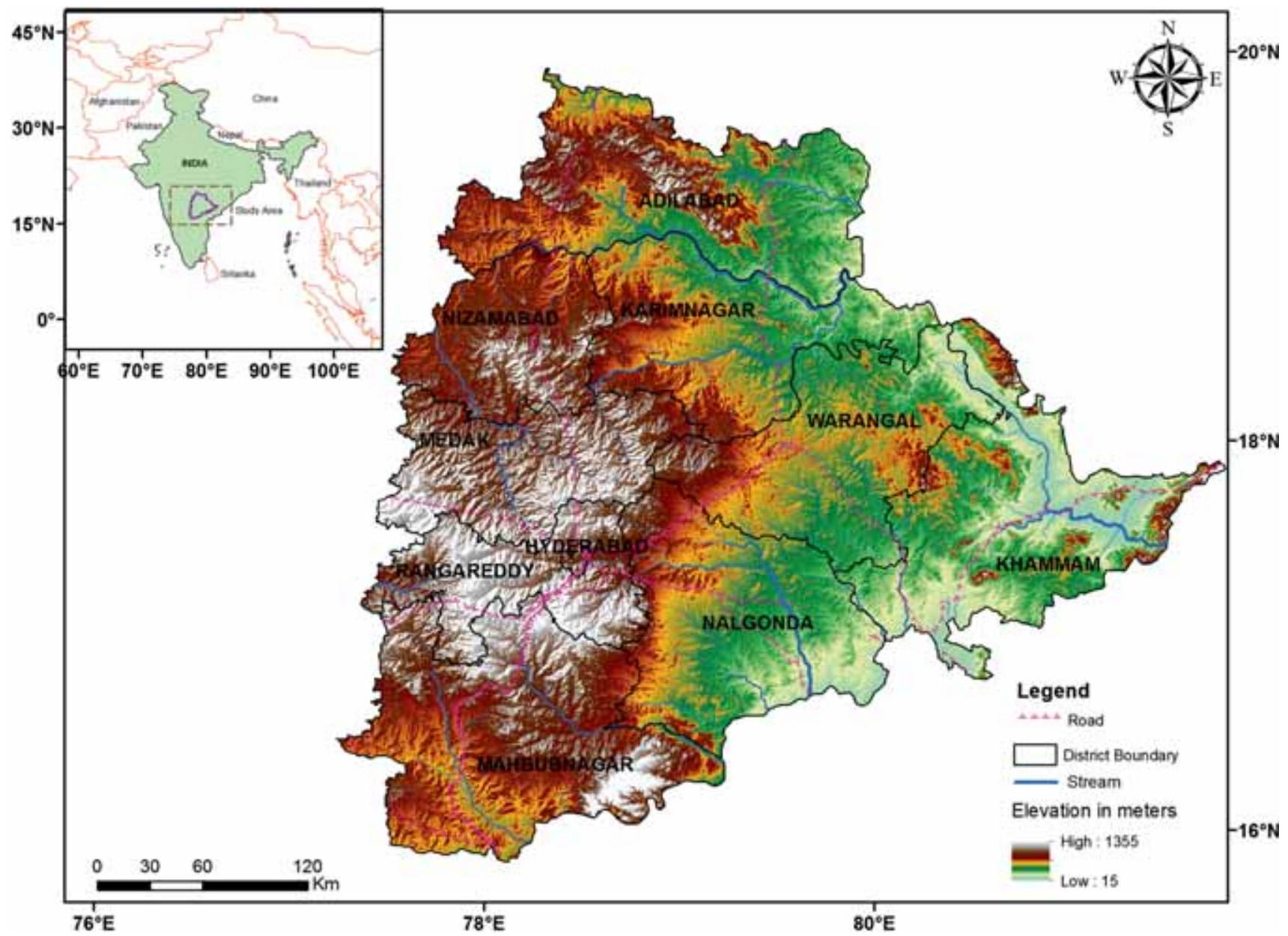

Figure 1. Location map of the study area (Telangana) India.

\section{Materials and methods}

\subsection{Study area}

This study covers the entire Telangana (figure 1), which is the 29th and the youngest province of the Federation of India, with a population of 35 million. The state has wide varieties of geological formations ranging from the oldest Archaean crystalline formations to the most recent alluvium. The gneissic complex with a structural fill of sedimentary formations and basin-fill of meta-sedimentary formations (Radhakrishna 1987) underlies a major part of the state. Geographically, the state is located in a semi-arid region, largely experiencing a hot and dry climate with an average temperature of $40^{\circ} \mathrm{C}$. The average annual rainfall is $900 \mathrm{~mm}$, mostly received during the monsoon season, between June and September. The Krishna and the Godavari rivers pass through the state and serve as major sources of surface water. Groundwater in this region mostly occurs in the weathered zones associated with fractures and joints, and the range of this weathered portion varies from 2 to $50 \mathrm{~m}$ (Saxena and Ahmed 2003; Reddy et al. 2010a,b). In hard rock terrains, the presence of deformation features such as joints and fractures facilitates the recharge and movement of groundwater (CGWB 2015). A large chunk of the state's rural population is dependent on groundwater sources for domestic and agricultural purposes. It is reported (Waldbott 1963; Karthikeyan et al. 1996; Gautam et al. 2010) that most of the locally sourced food, i.e., vegetables and milk are loaded with high fluoride content, thus the overall daily fluoride intake is higher than the permissible daily consumption limits. Due to climatic factors and a lack of proper water resource management, the state is among the most drought-prone areas in India, with a maximum fall in the decadal water-level fluctuation (CGWBAnnual 2015). 


\subsection{Methodology}

In this study, spatial information on various parameters such as geology, geomorphology, lineament, type of soils, land use and land cover, aquifer and depth of water table and rainfall were considered and the ArcGIS 10.3 software was used to create the thematic layers, for integration and to produce an output map. In order to demarcate the administrative boundaries of the Telangana, toposheets from the Survey of India (SOI) were used. The thematic geological map was prepared using the geology map published by the Geological Survey of India (GSI 1993). For preparing the aquifer map, the database from the CGWB report (CGWB 2015) was used. Topographic features geocoded at the scale of 1:50,000 at ISRO's Geo-portal, Bhuvan (http://bhuvan.nrsc.gov.in/gis/thematic/ index.php) which is used to construct lineament and geomorphology maps. The land use and land cover (LULC) map was prepared using semiautomatic classification methods from LISS III and Landsat data sets (https://earthexplorer.usgs. gov). Information on soil types was obtained from the Soil and Land Use Survey of India (http:// slusi.dacnet.nic.in/) and modified by using LISS III data sets. Slope and drainage density maps were prepared using SRTM DEM (30 m) (https:// lta.cr.usgs.gov/SRTM1Arc). The rainfall map was prepared using the mean monthly rainfall data of 15 yrs (2000-2015) obtained from the India Meteorological Department (http://www.imd.gov. in). The groundwater-level map was created from the groundwater-level data of 736 observation wells spread across the state (CGWB 2015).

In the ArcGIS platform, all collected attributes from different sources were modified into a raster form. The ArcGIS spatial analyst extension, which provides a rich suite of tools and capabilities for performing comprehensive, raster-based spatial analysis, was used for this purpose. Functions such as map algebra, combinational operators, data conversion and overlay tools of spatial analyst extension allowed integration to obtain the final PFC zones map. In order to understand the influence and importance of the controlling factors in the spatial distribution of fluoride, the GIS-based analytical hierarchy process (AHP) proposed by Saaty (1980) and the weighted overlay analysis method (WOAM) are employed. The AHP and WOAM combine the qualitative and quantitative approaches; therefore, in this study, an attempt is made to demonstrate a noble approach for the hydro-geological modelling of PFC zones by assigning different weights based on their relative importance, expert opinions and ranks obtained from the AHP technique. The model of PFC zones is validated by comparing the classes of the output map and published fluoride concentrations. Figure 2 gives a glimpse of the methodology followed in this study to prepare the map of PFC zones.

\subsubsection{Assigning weights and integration of thematic layers}

Literature and reports from the study area were referred to understand the relative importance of various environmental factors. In a regionalscale study, Handa (1975) analysed groundwater samples from different parts of the country and identified the mineralogical composition of crystalline igneous aquifer rocks, semi-arid climate, alkaline soils and to some extent, the tectonic settings to be key factors regulating the fluoride concentrations. Based on a study of geochemical parameters of groundwater and rock samples from 58 fluoride-rich areas in different parts of India, Saxena and Ahmed (2003) pointed out that the dissolution process determines the fluoride concentration in groundwater rather than an abundance of fluoride-bearing minerals in the host rocks. They also mentioned that $\mathrm{CaF}_{2}$ is greater in granite gneisses $(0.92 \%)$ followed by basalt $(0.56 \%)$ and dolerite $(0.45 \%)$. Mondal et al. (2009) reported that granitic and gneissic basement rocks of the Nalgonda area are enriched with respect to the presence of fluoride $(460-1706 \mathrm{mg} / \mathrm{kg})$ and advocated the rock-water interaction to be the main cause of fluoride contamination. The presence of fluoride-bearing minerals, such as apatite, biotite, muscovite, coupled with intense weathering and deformations of granite and granitic gneisses, results in the higher fluoride content Brindha et al. (2016). Rao (2009) argued that in the Varaha basin, the alkaline environment dominantly controls the leaching of fluoride from source rocks, followed by evapotranspiration, interaction time of water with the aquifer material and agricultural fertilisers. Arveti et al. (2011) considered the arid climate of the region, granitic host rocks and periodical droughts, resulting in low infiltration rates to be the main reason for a higher incidence of fluorosis in the Talupula region. Soils are the important natural sources of minerals containing fluoride and observed a range of fluoride 


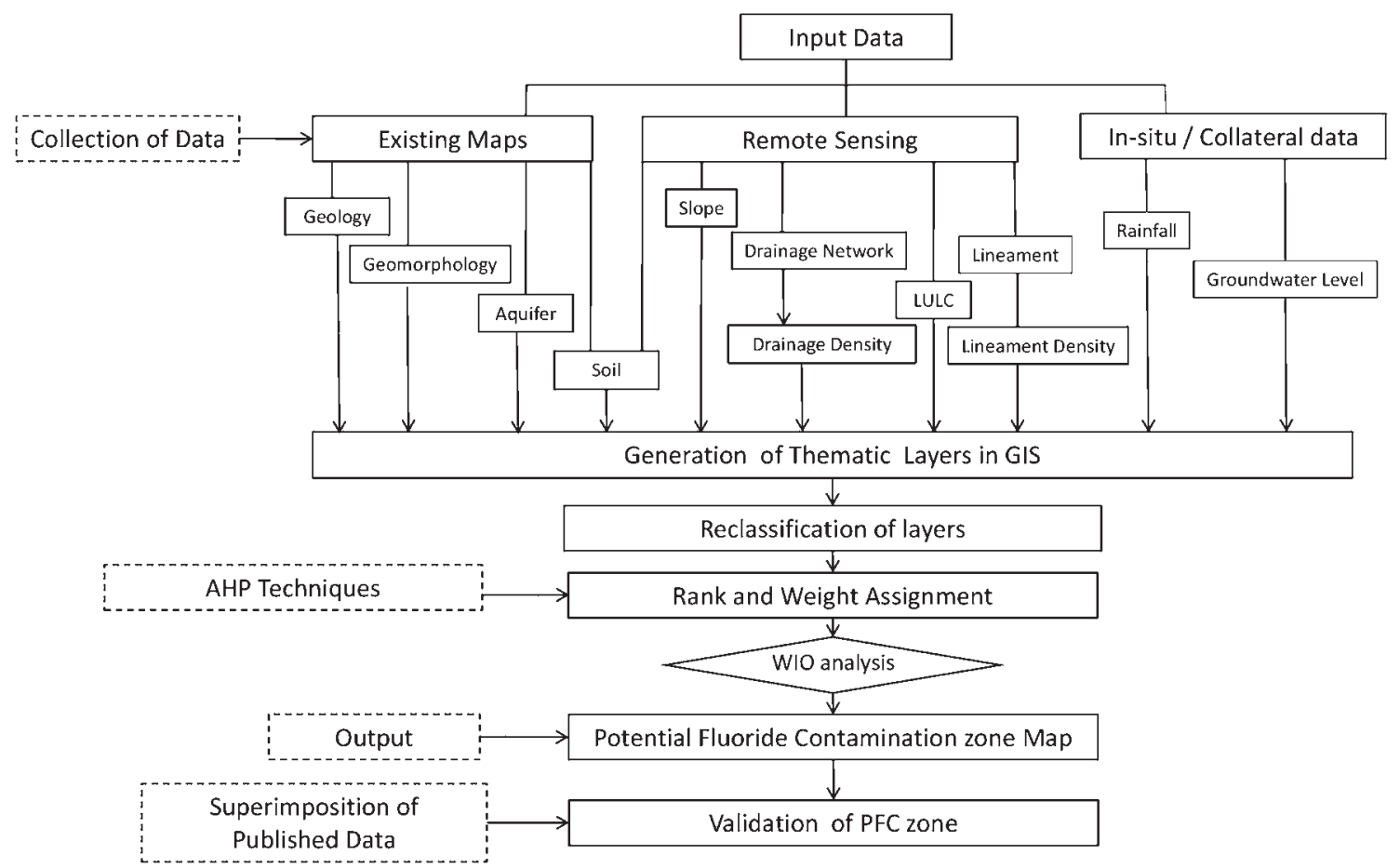

Figure 2. Step-by-step procedure followed for delineating PFC zone map for the state of Telangana.

generally varying from 200 to 300 ppm (Handa 1975; Ayoob and Gupta 2006). In semi-arid climatic regions, evaporation results in the formation of salts on the top layers of the soil. In soils with high fluoride content, the precipitate would contain a fluoride-rich salt. During subsequent rains, these fluoride-rich salts in the soil would leach along with the infiltrating rainwater, from the topsoil to the under-saturated zone. Few studies of Mondal et al. (2009) and Brindha et al. (2011) from Telangana have recorded a remarkable increase in the groundwater fluoride content during the post-monsoon samplings. From these studies, it is understood that though fluoride is a geogenic contaminant, its occurrence and enrichment in groundwater is controlled by multiple, but mostly natural, factors, including the mineralogy of host rocks, chemical and physical processes affecting dissolution and prevailing climatic and hydrological conditions.

It is evident that the opinions on various factors regulating the occurrence and enrichment of fluoride in groundwater differ from region to region, except for the geological setup. Almost every study links the occurrence of fluoride to mineralogical composition, though the type of fluoride-bearing minerals and their abundance may differ among source rocks. Therefore, in this study, catchment lithology is considered as a prominent factor. Note that the rocks belonging to the Archaean granite and gneissic complex form a basement of around $60 \%$ of the region; despite it, the occurrence of fluoride differs remarkably in different parts of the state. Understanding how the local variability in mineralogical composition affects the occurrence of fluoride in groundwater cannot be established due to a lack of detailed data, particularly pertaining to fluoride-bearing minerals in basement rocks. Therefore, other environmental variables commonly found to regulate fluoride concentrations are evaluated. Based on rigorous literature review, in addition, to geology (GG), lineament density (LD), surface morphology (GM), slope (SL), drainage density (DD), soil type (SI), land use land cover (LULC), aquifer (AQ), depth of groundwater level (GWL) and annual rainfall (RF) factors are identified to be influencing the enrichment of fluoride in groundwater. Similar factors were taken into consideration by Thapa et al. (2017) to delineate the fluoride contamination zone in Birbhum district. Additionally, the demographic data on the mandal (block) level obtained from Census-2011 (Census 2011) are applied to predict the risk of fluoride contamination in the state that the population faces. 


\subsubsection{AHP technique}

To prioritise the dominating variables, the AHP technique was used as a decision-aiding method to finalise the ranks assigned to different variables and subclasses. The AHP technique uses mathematical properties to resolve multi-class complex decisionmaking problems (Saaty 2001; Sener and Davraz 2013). In order to perform the AHP technique, first individual weights of specific variables and their subclasses are established based on their influence and expert opinions and an original pairwise comparison matrix is constructed (table 1 ). For $n$ number of factors, the pairwise comparison matrix consists of $n(n-1) / 2$ comparisons (Saaty and Kearns 2014). The column elements of the matrix are divided by the sum of each column. In a similar way, the sum of the row elements in the obtained matrix is divided by the number of elements in the rows, to obtain a normalised pairwise comparison matrix (table 2). The obtained normalised weights are within the range of $0-1$ with the sum being equal to 1. Additionally, the AHP technique provides mathematical operations to check the logical consistency of pairwise comparisons in order to avoid a certain level of consistency failure that generally occurs (Saaty and Kearns 2014). The consistency of pairwise comparison judgments is measured using the consistency ratio $(C R)$ using equation (1) and the upper limit for this ratio is 0.10 (Saaty 1980):

$$
C R=\frac{C I}{R I},
$$

where $R I$ is the random index whose value depends on the order of the matrix and $C I$ is the consistency index, obtained from

$$
C I=\frac{\lambda_{\max }-n}{n-1}
$$

where $\lambda$ is the largest eigenvalue of the matrix and $n$ is the number of thematic layers.

In any case, where the $C R$ calculation for the judgments is below 0.10 , it was demonstrated that the judgments exhibit a sufficient degree of consistency; furthermore, the assessment could be

\begin{tabular}{|c|c|c|c|c|c|c|c|c|c|c|}
\hline & GG & $\mathrm{LD}$ & GWL & $\mathrm{AQ}$ & SI & $\mathrm{RF}$ & GM & LULC & DD & SL \\
\hline GG & 1 & 1 & 2 & 4 & 4 & 6 & 6 & 8 & 8 & 10 \\
\hline LD & 1 & 1 & 2 & 3 & 3 & 4 & 4 & 8 & 8 & 9 \\
\hline GWL & 0.50 & 0.50 & 1 & 2 & 4 & 4 & 4 & 6 & 6 & 8 \\
\hline $\mathrm{AQ}$ & 0.25 & 0.33 & 0.50 & 1 & 2 & 3 & 3 & 4 & 5 & 8 \\
\hline SI & 0.25 & 0.33 & 0.25 & 0.50 & 1 & 2 & 2 & 4 & 6 & 9 \\
\hline $\mathrm{RF}$ & 0.17 & 0.17 & 0.25 & 0.33 & 0.50 & 1 & 2 & 6 & 6 & 6 \\
\hline GM & 0.17 & 0.17 & 0.25 & 0.33 & 0.50 & 0.50 & 1 & 2 & 4 & 6 \\
\hline LULC & 0.13 & 0.13 & 0.17 & 0.25 & 0.25 & 0.17 & 0.50 & 1 & 3 & 4 \\
\hline DD & 0.13 & 0.13 & 0.17 & 0.20 & 0.17 & 0.17 & 0.25 & 0.33 & 1 & 2 \\
\hline $\mathrm{SL}$ & 0.10 & 0.10 & 0.13 & 0.13 & 0.11 & 0.17 & 0.17 & 0.25 & 0.50 & 1 \\
\hline Total & 3.68 & 3.85 & 6.71 & 11.74 & 15.5 & 21.0 & 22.9 & 39.6 & 47.5 & 63.0 \\
\hline
\end{tabular}

Table 1. Original pairwise comparison matrix.

\begin{tabular}{|c|c|c|c|c|c|c|c|c|c|c|c|}
\hline & GG & $\mathrm{LD}$ & GWL & $\mathrm{AQ}$ & SI & $\mathrm{RF}$ & GM & LULC & DD & SL & Rank \\
\hline GG & 0.271 & 0.260 & 0.298 & 0.341 & 0.258 & 0.286 & 0.262 & 0.202 & 0.168 & 0.159 & 0.250 \\
\hline $\mathrm{LD}$ & 0.271 & 0.260 & 0.298 & 0.256 & 0.193 & 0.190 & 0.175 & 0.202 & 0.168 & 0.143 & 0.216 \\
\hline GWL & 0.136 & 0.130 & 0.149 & 0.170 & 0.258 & 0.190 & 0.175 & 0.152 & 0.126 & 0.127 & 0.161 \\
\hline $\mathrm{AQ}$ & 0.068 & 0.087 & 0.075 & 0.085 & 0.129 & 0.143 & 0.131 & 0.101 & 0.105 & 0.127 & 0.105 \\
\hline SI & 0.068 & 0.087 & 0.037 & 0.043 & 0.064 & 0.095 & 0.087 & 0.101 & 0.126 & 0.143 & 0.085 \\
\hline $\mathrm{RF}$ & 0.045 & 0.043 & 0.037 & 0.028 & 0.032 & 0.048 & 0.087 & 0.152 & 0.126 & 0.095 & 0.069 \\
\hline GM & 0.045 & 0.043 & 0.037 & 0.028 & 0.032 & 0.024 & 0.044 & 0.051 & 0.084 & 0.095 & 0.048 \\
\hline LULC & 0.034 & 0.032 & 0.025 & 0.021 & 0.016 & 0.008 & 0.022 & 0.025 & 0.063 & 0.063 & 0.031 \\
\hline DD & 0.034 & 0.032 & 0.025 & 0.017 & 0.011 & 0.008 & 0.011 & 0.008 & 0.021 & 0.032 & 0.020 \\
\hline SL & 0.027 & 0.026 & 0.019 & 0.011 & 0.007 & 0.008 & 0.007 & 0.006 & 0.011 & 0.016 & 0.014 \\
\hline
\end{tabular}

Table 2. Normalised comparison matrix. 
continued. If the $C R$ is above 0.10 , then it indicates that the judgments are inconsistent. In this case, the judgments need to be reviewed to reduce the $C R$ (Saaty 1994). In the present context, the $C R$ is computed as 0.056, which is less than the standard criteria 0.10 , hence the rates taken in this study are consistent. The final ranks for each criterion are used in the WOAM for the generation of final $\mathrm{PFC}$ zones map.

\subsubsection{Weighted overlay analysis method}

WOAM is a method for the combined analysis of multi-class maps. Input layers used in this study have different numbering systems with different ranges. In order to perform an overlay analysis, each cell for each criterion must be reclassified into a common numerical scale with the least to the most favourable (Thapa et al. 2017).

After the successful assignment of appropriate ranks and weights to different input factors and their respective sub-classes using the AHP technique (table 3), WOAM was adopted to delineate the final PFC zone using the following equation:

$$
\mathrm{PFC}=\sum_{i=1}^{n, m}(A x B y),
$$

where $A$ represents the rank of the factor class, $B$ represents the weight of the factor sub-class, $x(x=1,2,3, \ldots, m)$ represents the factor maps and $y(y=1,2,3, \ldots, n)$ represents the factor class.

\section{Results and discussions}

\subsection{Geological and other controlling factors}

Telangana is endowed with various rock types from the Archaean to the Quaternary age. Granite, granite gneiss and granitoid gneiss both younger and older phases, collectively known as the peninsular gneiss complex (PGC) is the predominant lithology $(56.70 \%)$ with major distribution in the central part of the study area (figure 3a). The gneissic complex is overlain by basaltic lava flows in the northwestern part and is intruded by several younger rocks, namely, granites, dolerites, pegmatites, quartzites, etc. Dharwars, comprising amphibolites, gneisses, schists and quartzites, occur as narrow isolated bands within granites in Mahbubnagar, Nalgonda, Khammam, Warangal, Karimnagar and Adilabad districts. The Cuddapah supergroup of rocks occur in parts of Nalgonda and Mahbubnagar districts. The Pengangas, which are considered as the equivalent of the Pakhals, are exposed in Adilabad district. Gondwana formations, comprising a lower group of rocks, the Talchirs, Barakars and Kamthis and the upper group of rocks, the Maleris, Kotas and Chikialas were occupied in parts of Khammam, Warangal, Karimnagar and Adilabad districts. Horizontal to sub-horizontal disposed lava flows of the Deccan traps covering $\sim 8210 \mathrm{~km}^{2}$ occur in parts of Adilabad, Nizamabad, Medak, RangaReddy and Mahbubnagar districts. The thickness of the individual flow varies from a few metres to as much as $30 \mathrm{~m}$ with a total thickness of more than $200 \mathrm{~m}$ at places (CGWB 2015).

It is known that a high-level network/intersection of lineaments represents a high degree of deformation (Shaji et al. 2007) and in hard rock terrains, these structural features provide extended surfaces for the interaction of water with surrounding rocks containing fluoride-bearing minerals (Saxena and Ahmed 2003). Several previous studies, such as Handa (1975), Ramesam and Rajagopalan (1985) and Shaji et al. (2007), have related the abnormal level of fluoride in groundwater with a high density of lineaments/fractures. In the case of Telangana, the basement is mostly composed of deformed PGC, therefore, structural features (secondary porosity) in the formations allow the water-rock interaction (Jacks et al. 2005; Brindha et al. 2011). Hence, among the identified factors, lineament density is given second top preference (AHP Rank-0.215). This is in contrast to the study by Thapa et al. (2017), in which, the study area (Birbhum district) is primarily composed of relatively younger formations. Lineament density (LD) map of the Telangana was extracted from the Bhuvan portal (http://bhuvan.nrsc.gov. in/gis/thematic/index.php). It suggests structural deformations in basement rocks, which are represented as several linear or curvilinear features, indicating the presence of faults, dykes, joints, fractures and drainage parallel. The major trends of lineaments present in the study area are NE-SW, E-W and ENE-WSW. The high lineament density region encompasses in most parts of Nalgonda, Mahabubnagar, the southern part of Karimnagar, the eastern part of Khammam and the central part of Medak areas. The low-density region includes most of Adilabad, RangaReddy and Hyderabad areas (figure $3 \mathrm{~b}$ ).

The mean GWL map (figure 4a) reveals that the water table in the study area varies between 0 and 
Table 3. Factors and associated co-variables, regulating the enrichment of fluoride in groundwater, respective AHP ranks and assigned weightage.

\begin{tabular}{|c|c|c|c|c|}
\hline $\begin{array}{l}\text { Sl. } \\
\text { no. }\end{array}$ & Factor & $\begin{array}{l}\text { AHP } \\
\text { rank }\end{array}$ & Co-variables & Weightage \\
\hline \multirow[t]{10}{*}{1} & \multirow{10}{*}{$\begin{array}{l}\text { Geology/lithology of catchment } \\
\text { (GG) }\end{array}$} & \multirow[t]{10}{*}{0.250} & PGC & 10 \\
\hline & & & Migmatite & 09 \\
\hline & & & Charnockite, Dharwar supergroup & 08 \\
\hline & & & Closepet granite, khondalite & 07 \\
\hline & & & Barakar formation & 06 \\
\hline & & & $\begin{array}{l}\text { Kurnool group, Srisailam formation, Kaimur and } \\
\text { Semri group }\end{array}$ & 05 \\
\hline & & & Jurassic cretaceous formation, laterite and bauxite & 04 \\
\hline & & & $\begin{array}{l}\text { Pakhal group, Kamthi formation, Talchir } \\
\text { formations, coastal and glacial sediments, Maleri } \\
\text { formation }\end{array}$ & 03 \\
\hline & & & $\begin{array}{l}\text { Deccan traps, Chikiala formation, Banganapalli } \\
\text { formation, Sullavai group, granophyre, Bhima } \\
\text { group }\end{array}$ & 02 \\
\hline & & & Rajahmundary formation & 01 \\
\hline \multirow[t]{3}{*}{2} & \multirow{3}{*}{$\begin{array}{l}\text { Occurrence of lineament, joints and } \\
\text { faults (LD) }\end{array}$} & \multirow[t]{3}{*}{0.215} & High & 08 \\
\hline & & & Medium & 04 \\
\hline & & & Low & 02 \\
\hline \multirow[t]{5}{*}{3} & \multirow[t]{5}{*}{ Groundwater table depth (GWL) } & \multirow[t]{5}{*}{0.160} & $0-5 \mathrm{~m}$ & 02 \\
\hline & & & $5-10 \mathrm{~m}$ & 08 \\
\hline & & & $10-20 \mathrm{~m}$ & 07 \\
\hline & & & $20-40 \mathrm{~m}$ & 06 \\
\hline & & & $40-50 \mathrm{~m}$ & 04 \\
\hline \multirow[t]{9}{*}{4} & \multirow[t]{9}{*}{ Aquifer lithology (AQ) } & \multirow[t]{9}{*}{0.105} & Gneisses and associated rock formations & 09 \\
\hline & & & Charnockite/granite & 08 \\
\hline & & & Quartzite & 07 \\
\hline & & & Alluvium & 06 \\
\hline & & & Laterite/sandstone & 05 \\
\hline & & & Schist & 04 \\
\hline & & & Limestone & 03 \\
\hline & & & Basalt & 02 \\
\hline & & & Shale & 01 \\
\hline \multirow[t]{4}{*}{5} & \multirow[t]{4}{*}{ Surface soil type (SI) } & \multirow[t]{4}{*}{0.09} & Red loamy soil & 08 \\
\hline & & & Mixed red and black soil & 05 \\
\hline & & & Red sandy soil & 04 \\
\hline & & & Laterite & 02 \\
\hline \multirow[t]{5}{*}{6} & \multirow[t]{5}{*}{ Annual rainfall $(\mathrm{RF})$} & \multirow[t]{5}{*}{0.07} & Very low (below $850 \mathrm{~mm}$ ) & 06 \\
\hline & & & Low $(850-900 \mathrm{~mm})$ & 05 \\
\hline & & & Medium $(900-950 \mathrm{~mm})$ & 04 \\
\hline & & & High $(950-1000 \mathrm{~mm})$ & 03 \\
\hline & & & Very high (above $1000 \mathrm{~mm}$ ) & 02 \\
\hline \multirow[t]{4}{*}{7} & \multirow[t]{4}{*}{ Geomorphology (GM) } & \multirow[t]{4}{*}{0.05} & Alluvial plains and terraces & 04 \\
\hline & & & Extrusive (lava) plains & 03 \\
\hline & & & Planation surfaces including duricrusts & 02 \\
\hline & & & Denudational ridges or hills and valleys & 01 \\
\hline \multirow[t]{6}{*}{8} & \multirow[t]{6}{*}{ Land use land cover (LULC) } & 0.03 & Cultivated land & 03 \\
\hline & & & Settlement & 03 \\
\hline & & & Forest area & 02 \\
\hline & & & Barren/waste land & 02 \\
\hline & & & Water bodies & 01 \\
\hline & & & Uncultivable land & 01 \\
\hline
\end{tabular}


Table 3. (Continued.)

\begin{tabular}{|c|c|c|c|c|}
\hline $\begin{array}{l}\text { Sl. } \\
\text { no. }\end{array}$ & Factor & $\begin{array}{l}\mathrm{AHP} \\
\text { rank }\end{array}$ & Co-variables & Weightage \\
\hline \multirow[t]{5}{*}{9} & Drainage density (DD) & 0.02 & Very low (less than 0.2 stream per $\mathrm{km}^{2}$ ) & 05 \\
\hline & & & Low $\left(0.2-0.4\right.$ stream per $\left.\mathrm{km}^{2}\right)$ & 04 \\
\hline & & & Medium $\left(0.4-0.6\right.$ stream per $\left.\mathrm{km}^{2}\right)$ & 03 \\
\hline & & & High $\left(0.6-0.8\right.$ stream per $\left.\mathrm{km}^{2}\right)$ & 02 \\
\hline & & & Very high $\left(0.8-1.13\right.$ stream per $\left.\mathrm{km}^{2}\right)$ & 01 \\
\hline \multirow[t]{4}{*}{10} & Slope (SL) & 0.01 & $0-3 \%$ & 04 \\
\hline & & & $3-6 \%$ & 03 \\
\hline & & & $6-9 \%$ & 02 \\
\hline & & & $>9 \%$ & 01 \\
\hline
\end{tabular}

$50 \mathrm{~m}$ below ground level (BGL). In about 18.3\% area, the groundwater is available at very shallow depths (0-5 m BGL). Additionally, in half of the Telangana $(47.6 \%)$, groundwater is present at relatively shallow depths (between 5 and 10 m BGL). Overall, for about $66 \%$ of the study area, the availability of groundwater is at $0-10 \mathrm{~m}$ depth. In most parts of the Adilabad and Khammam areas, the groundwater depth varies from 0 to $10 \mathrm{~m}$ BGL. For around $29.7 \%$ of the study area, the depth of groundwater varies from 10 to $20 \mathrm{~m}$ BGL. At few patches, groundwater occurs at 20-40 $\mathrm{m}$ depth (4.2\% area) and also deeper than $40 \mathrm{~m}$ (0.21\%), which indicate extreme water stress areas.

Aquifers are the water-bearing rock formations, in which water percolates, stored and transmitted from top layers of rocks or soils. The type of aquifer rock, mineralogical composition and residence time are the major factors determining the quality of groundwater in a region. Thus, the concentration of contaminants may increase with a longer residence time. In the study area, groundwater occurs in aquifers of different geological formations right from the Archaean crystalline to the most recent alluvium (figure $4 \mathrm{~b}$ ). The crystalline rocks, which occupy $\sim 70 \%$ of the area, generally lack primary porosity and only secondary porosity is developed due to weathering, fracturing and the development of solution cavities and channels. As mentioned earlier, the depth of the weathered zone in the study area varies from 2 to $50 \mathrm{~m}$ BGL and fractures may extend up to $100 \mathrm{~m}$ depth. Pakhals, Penganga and Sullavais are known to be relatively poor to moderate potential aquifers and basalts are hard and compact and possess meagre primary porosity. Rocks belonging to the Gondwana formations (i.e., Talchirs, Barakaras and Kamthis) form semi-consolidated formations and yield more groundwater than consolidated crystalline rocks. Unconsolidated alluviums occupy areas along the Krishna and the Godavari rivers and their tributaries.

Telangana has a wide variety of soils viz., red soil, lateritic soils and medium black soils (figure 4c). A large part of the state $(59.9 \%)$ is occupied by red sandy soils with loamy sub-soils covering the entire Nalgonda district, a major part of Mahabubnagar, Warangal, Karimnagar and Nizamabad districts. Red loamy soils cover another $31.8 \%$ area. The red soils are deficient in organic matter and poor in nutrients, but rich in phosphoric acid. The moisture-holding capacity of red soils is poor and irrigation is frequently required. Medium black soils spread to $3.0 \%$ area and for about $4.6 \%$ area is taken over by mixed black and red soils. Laterite soils $(0.71 \%$ area) are restricted to the central part of Medak district.

The rainfall distribution patterns across the state are illustrated in figure $4(\mathrm{~d})$. It revealed that the minimum rainfall is $735 \mathrm{~mm}$ in the state and for about $20.5 \%$ of an area covering a major portion of Mahabubnagar and Nalgonda districts, annual rainfall is below $850 \mathrm{~mm}$. The areas receiving annual rainfall between 850 and 900; 900 and 950; and 950 and $1000 \mathrm{~mm}$ covers 16.7, 23.8 and $26.3 \%$ areas, respectively. Just $12.6 \%$ of the total area covering the northern part of Adilabad receives more than $1000 \mathrm{~mm}$ rainfall annually.

The geomorphology of any area is a manifestation of the underlying geology and is crucial for groundwater-related studies (Machiwal et al. 2011). The study area consists of different types of morphology (figure 5a), dominated by plantation surfaces including duricrusts (57.4\% of area). Denudational ridges or hills and valleys $(23.2 \%)$, extrusive lava plateaus $(7.9 \%)$, structural valleys and plains $(6.7 \%)$, structural plateaus $(2.7 \%)$ and 


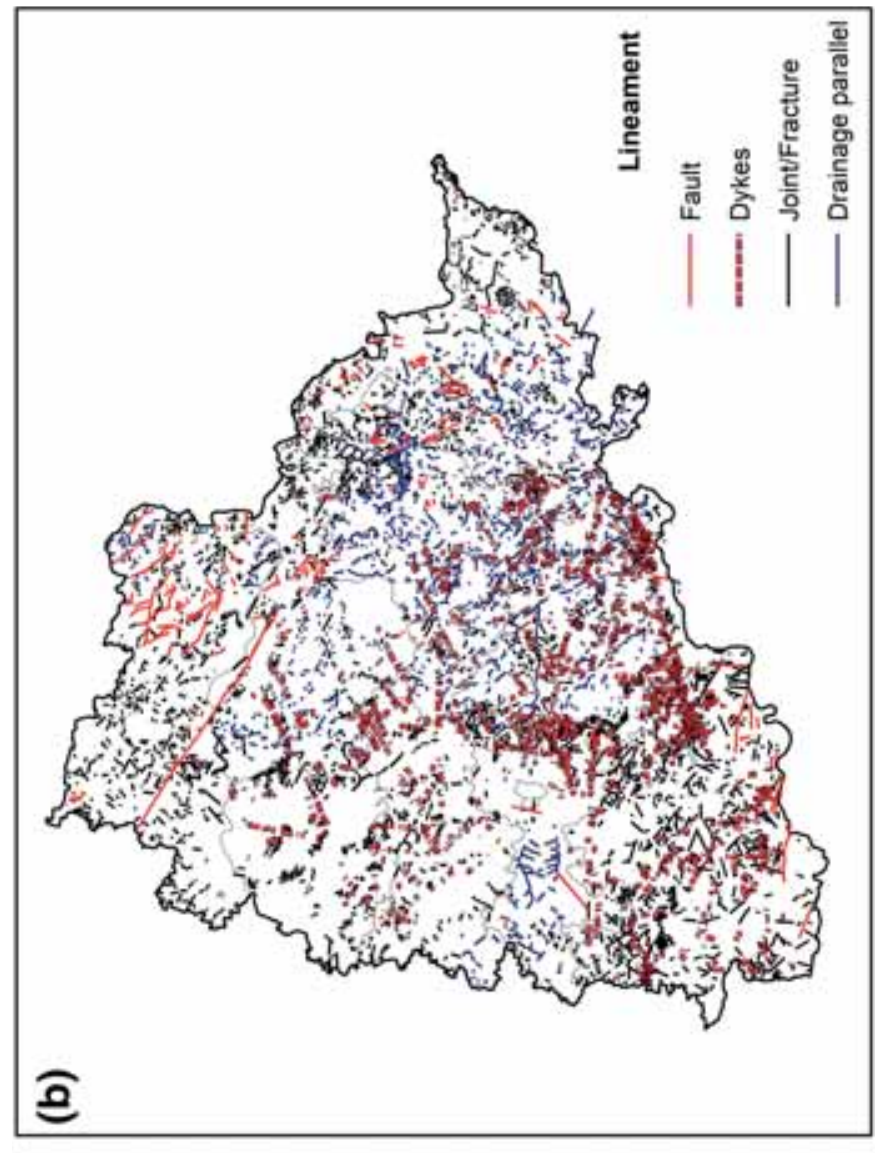

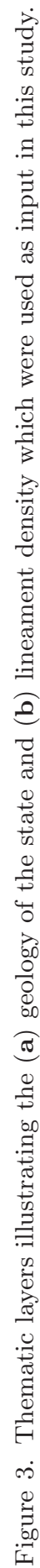

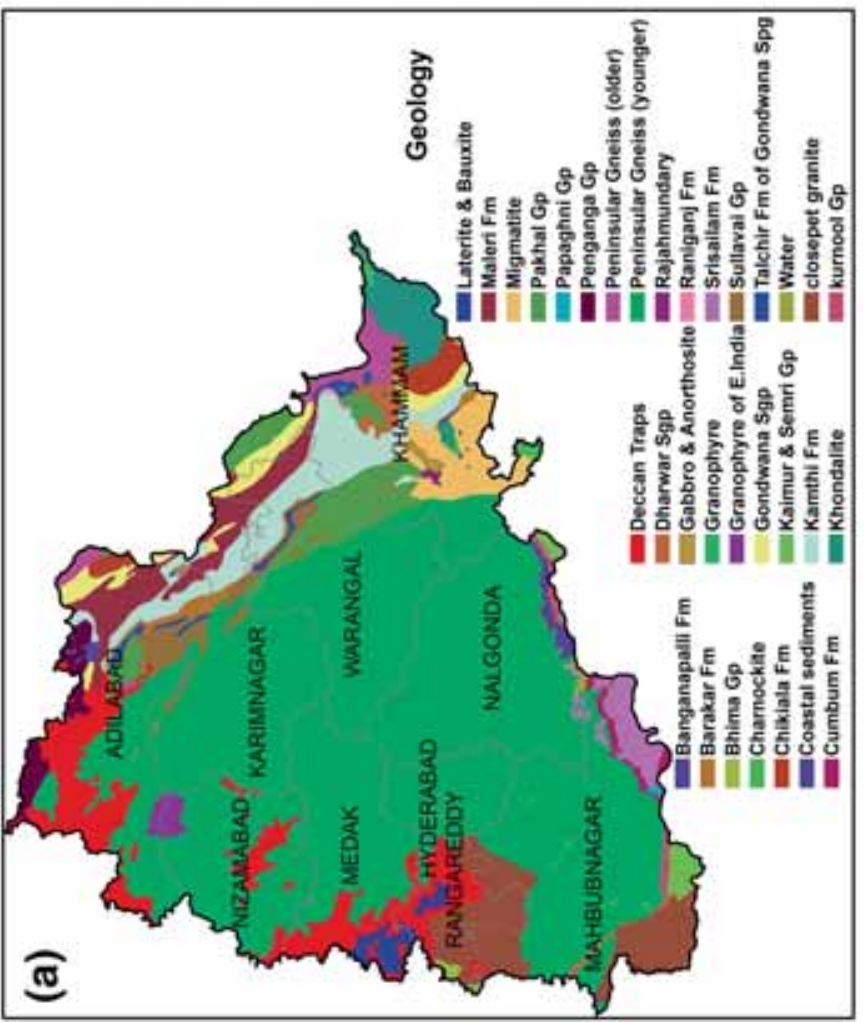



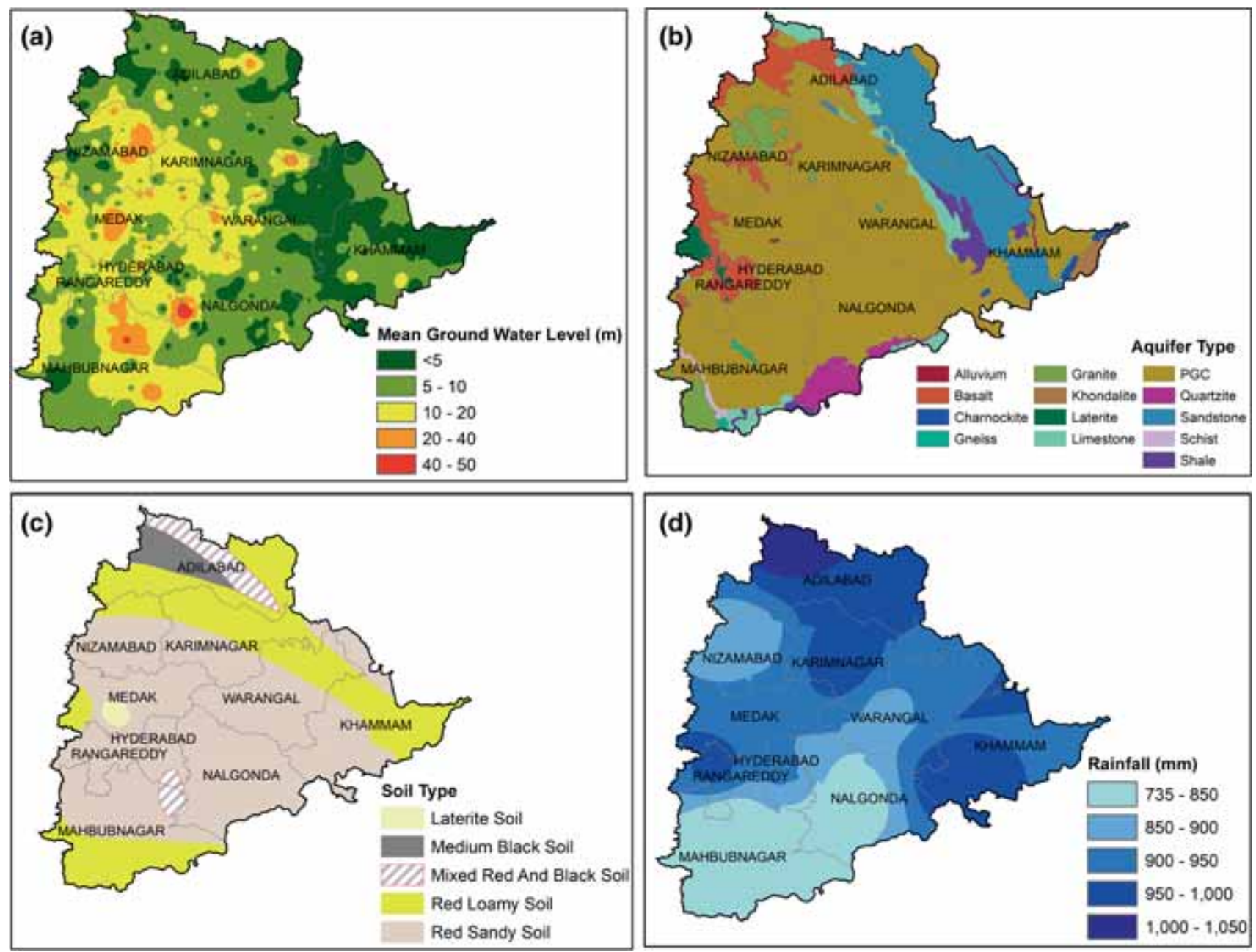

Figure 4. Thematic layers illustrating the (a) mean groundwater level, (b) type of aquifer, (c) soil type and (d) annual rainfall across Telangana. These variables were used as input in this study.

alluvial planes followed by tracer deposits $(1.4 \%)$, etc.

Land cover, nature of land use and change in land-use patterns significantly affect the infiltration rate, availability and quality of groundwater Lerner and Harris (2009). Cultivated land (39\%) encompasses a major portion of the state, followed by forests $(22.7 \%)$, wastelands $(12.5 \%)$, wetlands $(7.9 \%)$, water bodies $(7.2 \%)$ and open forest $(5.4 \%)$. Only a small proportion of land in the study area $(5.3 \%)$ is under settlements (figure $5 \mathrm{~b}$ ).

The drainage density is a measure of how well or how poorly a watershed is drained by stream channels. Areas with less permeable rocks normally have well-developed drainage networks and are characterised by higher runoff and low infiltration rates. Since the drainage density can indirectly indicate the solubility of fluoride minerals present in soils/rocks with surface runoff and permeability, it was considered as one of the indicators of contamination zones. The entire state can be classified in the five sub-classes (figure $5 \mathrm{c}$ ). About $39.3 \%\left(0.6-0.8 \mathrm{~km} / \mathrm{km}^{2}\right)$ of the area falls under the 'high, drainage density region, followed by 'very high' (0.8-1.1 km/ $\left.\mathrm{km}^{2} ; 22.5 \%\right)$, 'moderate' $\left(0.4-0.6 \mathrm{~km} / \mathrm{km}^{2} ; 30.8 \%\right)$, 'low' $\left(0.2-0.4 \mathrm{~km} / \mathrm{km}^{2}\right.$; $6.1 \%)$ and 'very low' $\left(0.02 \mathrm{~km} / \mathrm{km}^{2} ; 1.2 \%\right)$ drainage density regions.

The degree of the surface slope in any watershed determines the surface runoff and the amount of water available for infiltration. It is known that a gentle slope improves the chances of percolation of water from the surface and promotes the interaction between water and minerals in soils. The surface slope percentage in Telangana varies from 0 to $30 \%$ (figure $5 \mathrm{~d}$ ) and is categorised into five different classes. In Telangana, about $39.7 \%$ of the land is characterised by the low slope $(0-3 \%)$, where the nearly flat terrain promotes high infiltration rates. The areas with 3-6\% slope occupy about $35 \%$ of the total area and are considered as promising areas for surface water storage and subsequent 

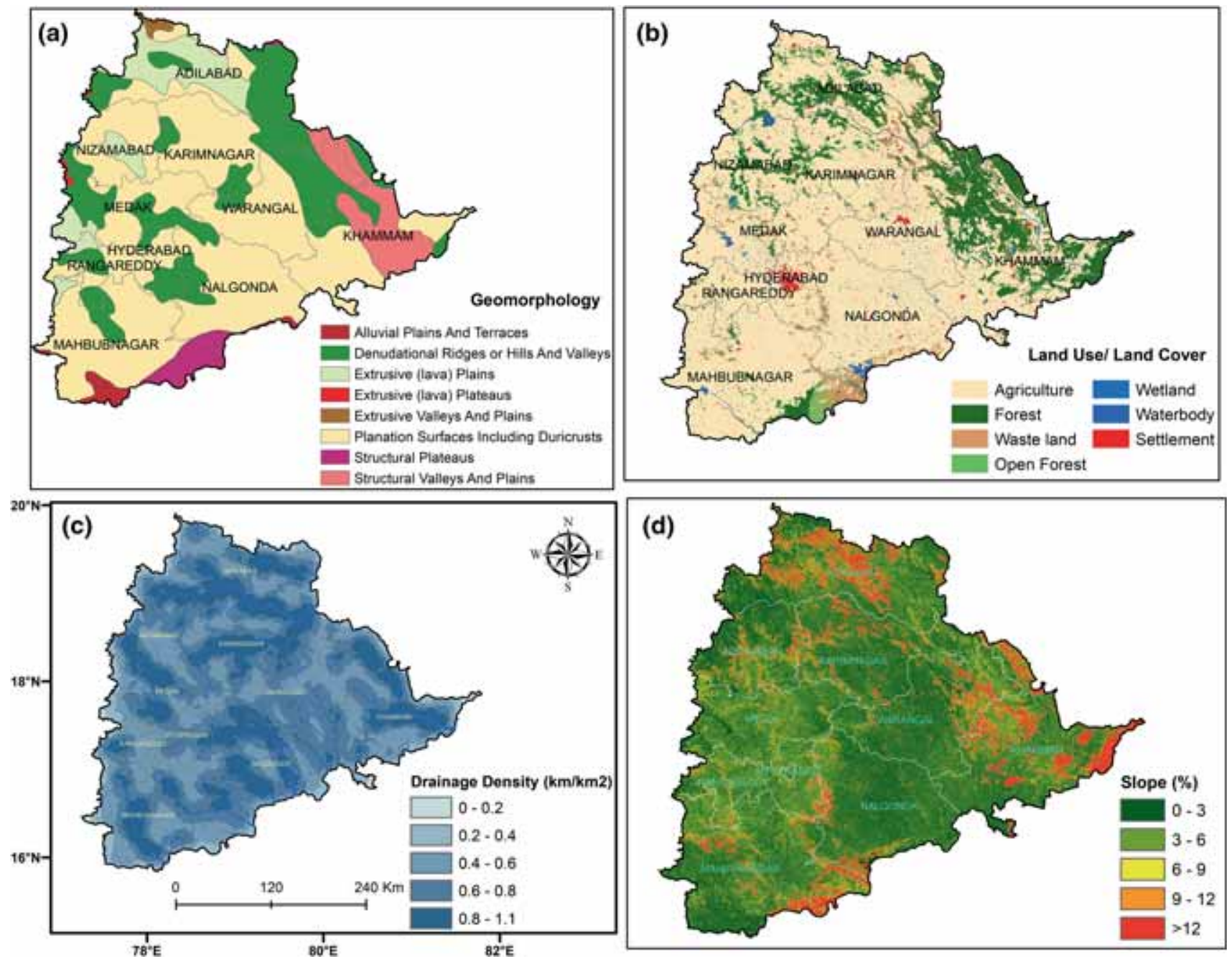

Figure 5. Thematic layers illustrating the (a) geomorphology, (b) land use and land cover, (c) drainage density and (d) slope of the study area. These variables were used as input in this study.

infiltration due to the slightly undulating topography. The areas having a slope of $6-9 \%$ ('moderate' category) covers $9.8 \%$ and are areas of relatively high runoff and low infiltration. The fourth $(9-12 \%)$ and fifth $(>12 \%)$ together cover $15.5 \%$ of the total land area in the state and are characterised by poor infiltration rates due to the higher slope and quick runoff.

\subsection{PFC zones map}

The final PFC zone map was generated by the integration of all input factor maps using a weighted overlay analysis method with GIS techniques: where $x$ represents the weight of the individual co-variables of a factor and $y$ represents the AHP rank of a respective factor.

Figure 6(a) illustrates the fluoride distribution in Telangana. The final PFC zone map is categorised into four broad classes from 'low' to 'very high' to demonstrate areas under endemic fluorosis. In the PFC zones stretch, the category 'very high' accounts for $17.6 \%$ (or $19,726 \mathrm{~km}^{2}$ ) of the study area; 'high' PFC zone constitutes about $15.8 \%$ (or $17,708 \mathrm{~km}^{2}$ ) of land, 'medium' PFC class accounts for $32.7 \%$ (or $36,649 \mathrm{~km}^{2}$ ), whereas $33.9 \%$ (or $37,994 \mathrm{~km}^{2}$ ) of the total area falls under the low PFC zone. The category 'low' with fluoride

$$
\begin{aligned}
\mathrm{PFC}= & \sum_{i=1}^{n, m} G G x G G y+A Q x A Q y+L D x L D y+G W L x G W L y+S I x S I y+R F x R F y \\
& +G M x G M y+L U L C x L U L C y+D D x D D y+S L x S L y
\end{aligned}
$$



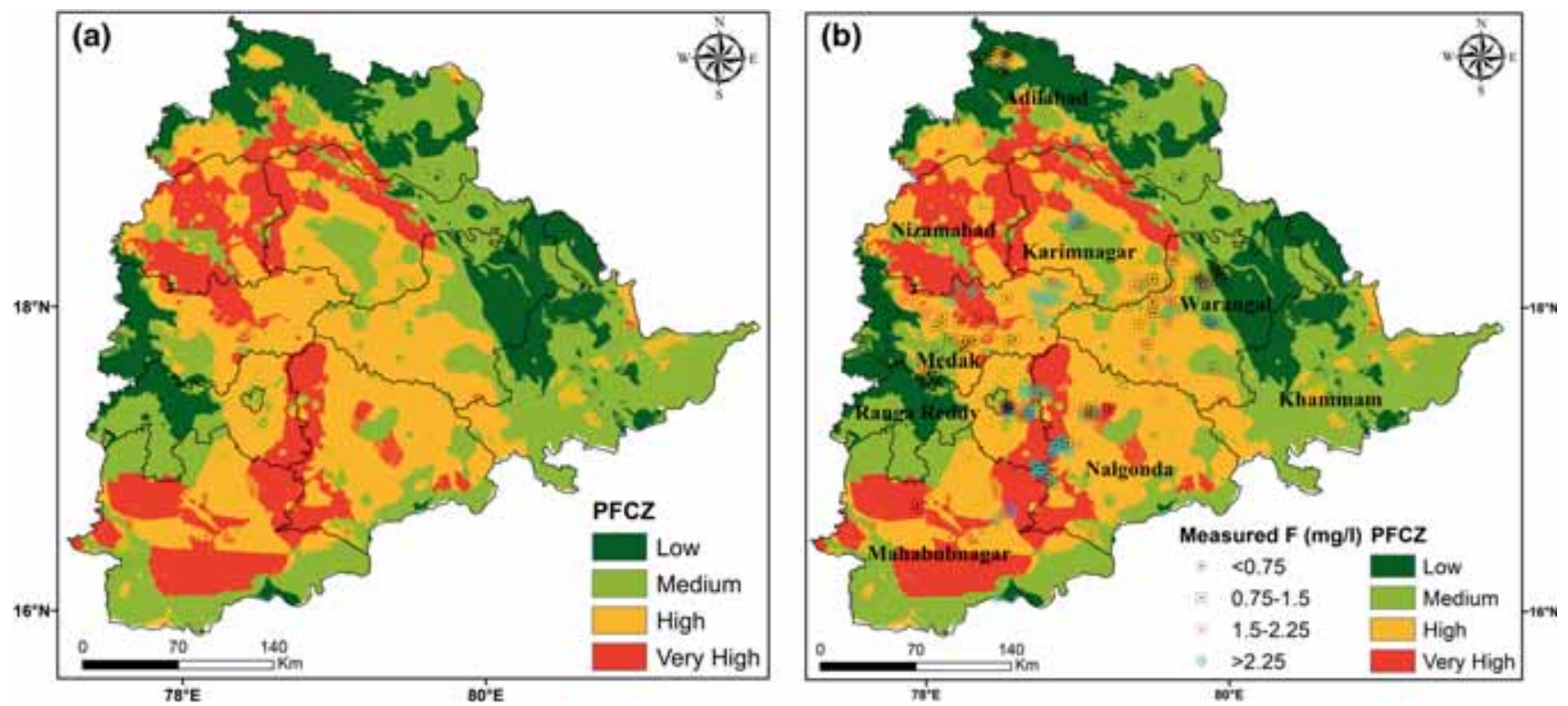

Figure 6. (a) PFC zone map of Telangana and (b) distribution of measured fluoride data, superimposed for validation.

concentration $<0.75 \mathrm{mg} / \mathrm{l}$ represents the area considered safe for utilising groundwater for drinking purposes. The second category 'medium' with fluoride concentration $\geq 0.75-1.5 \mathrm{mg} / \mathrm{l}$ includes regions where caution is needed while utilising groundwater for drinking and cooking purposes. Areas under 'high' ( $>1.5-2.25 \mathrm{mg} / \mathrm{l})$ and 'very high' ( $\geq 2.25)$ zones together cover $28 \%$ area of the state. In this area, the groundwater should not be used for drinking and cooking purposes and even locally, source food should be avoided. Very high and high PFC zones are observed mainly in the central part of the study area covering most parts of Nalgonda, Mahabubnagar and Nizamabad districts. In these areas, Archaean (PGC) basement rocks were greatly deformed, as reflected by high lineament densities. Besides, the PFC zones map suggests that the groundwater in areas with greater groundwater levels is more susceptible to fluoride contamination.

\subsection{Validation of the model}

In order to be accurate in prediction, the map of PFC zones needs to be validated by comparing the map classes and classes identified in the field. This requires a set of randomly acquired samples (class of a pixel) and verification of it through measured data. Confusion/error matrix known as a site-specific accuracy-assessment method is used for this purpose. This matrix is based on assumptions that pixels are pure and there is no location and ground data error (Foody 2002, 2008). In this process, measured fluoride data from published literature were collected. In the past three decades, several studies on the fluoride problem in Telangana were published; however, most of the studies provide averaged data at the block level. Therefore, about only 400 measured data from Kumar et al. (1991), Sreedevi et al. (2006), Mondal et al. (2009), Reddy et al. (2010a, b), Brindha et al. (2011), Sudarshan (2015), Narsimha and Sudarshan (2016), Narsimha and Sudarshan (2017) and Satyanarayana et al. (2017) were considered. Similar to the map of PFC zones, the measured data were classified in four categories $(<0.75,0.75-1.5,1.5-2.25$ and $>2.25 \mathrm{mg} / \mathrm{l})$ and the thus-prepared point layer of fluoride concentration was superimposed over the PFC zones map (figure 6b). As the samples were collected in different years and during different seasons, normalisation was performed by making $5 \mathrm{~km} \times$ $5 \mathrm{~km}$ grids for the entire study area. All samples falling within the grid were averaged. This process of normalising data is also helpful in scaling locally measured values to regional PFC zones map (Stehman et al. 2003). In this process, a total of 198 grids were made which covered all 400 sample locations. If more than one sample is not available in a particular grid, then the single value was retained for the validation process. Confusion/error matrix of observed vs. predicted is made and classwise accuracy was calculated (table 4). For the 'low' category out of the total 44 predicted grids, 
Table 4. Confusion/error matrix to assess the accuracy of the PFC zone map predictions.

\begin{tabular}{lccccc}
\hline & \multicolumn{5}{c}{ Observed } \\
\cline { 2 - 6 } & Low & Medium & High & Very high & Summary \\
\hline Predicted & 33 & 6 & 2 & 0 & 41 \\
Low & 10 & 22 & 16 & 1 & 49 \\
Medium & 0 & 10 & 66 & 8 & 84 \\
High & 1 & 1 & 7 & 15 & 24 \\
Very high & 44 & 39 & 91 & 24 & 198 \\
Summary & 75.0 & 56.4 & 72.5 & 62.5 & \\
Accuracy (\%) & & & & & \\
\hline
\end{tabular}

33 coincide with the measured category. Similarly, for the 'medium' category, the overlap was 39 predicted vs. 22 measured; for the 'high' category, it was 91 predicted vs. 66 measured; for the 'very high' category, coincidence was 24 predicted vs. 15 measured. Thus, end-user accuracy of $75,64,58$ and $68.5 \%$ was achieved for the 'low', 'medium', 'high' and 'very high' categories, respectively. Overall, the map of PFC zones predicted the occurrence of fluoride contamination with $68.7 \%$ accuracy. The level of accuracy of the map of the proposed PFC zones of Telangana is lower than the one prepared by Thapa et al. (2017) for the Dwarka basin of Birbhum district $(83.2 \%)$. It is obvious, as the area under this study of the entire Telangana $\left(112,077 \mathrm{~km}^{2}\right)$ is 130 times bigger than that of the Dwarka basin $\left(858 \mathrm{~km}^{2}\right)$. Consequently, for validation, in comparison with one sample for every $4.35 \mathrm{~km}^{2}$ for the Dwarka basin, it is one sample for $280 \mathrm{~km}^{2}$ in the present study. The statistical model on geogenic fluoride contamination in groundwater at a global scale (Amini et al. 2008) predicted the occurrence of fluoride in different regions across the world by 30-70\% accuracy. Therefore, it can be mentioned that in spite of being a regional scale study with a limited set of measured data, the proposed model performed well and is robust for predicting the enrichment of fluoride in groundwater.

\subsection{Management of the PFC zones}

This study was carried out to visualise the extent of fluoride contamination in Telangana, which is imperative for the planning and implementation of municipal drinking water supply programmes. Integration of the map of PFC zones with the mandal-level demographic data revealed that the area (33\% of the total land area of the state) with high to very high fluoride concentration is house to about 20 million people $(58 \%$ of the population) in Telangana (figure 7). Dental and skeletal fluoroses is irreversible and the only remedy is prevention. The most appropriate step is to provide safe drinking water either by in-situ defluoridation or by supplying municipal water. In addition, improving the nutritional level of the population also reduces the vulnerability to fluorosis (Susheela 1999). At first, the locally designed defluoridation process was opted as the immediate solution, in the affected parts of the Nalgonda district. This was a two-step process, in which a combination of aluminium and lime was used for the in-situ removal of fluoride from ground water. Subsequently, this technique was named as the Nalgonda technique (Nawlakhe et al. 1975). Later researchers found this technique to be not so effective as even after treatment a significant proportion of fluoride remained in the treated water. Later on, drinking water pipelines were laid down for some of the worst affected villages to supply purified Krishna river water. Reverse osmosis plants were also set up to treat groundwater. However, none of them provided a permanent solution. To provide a long-term solution, the current government of Telangana planned a flagship programme known as Mission Bhagiratha (http:// missionbhagiratha.telangana.gov.in/). Under this plan, local river water will be purified using existing and newly constructed water treatment plants (figure 7) and supplied to each household of the state. In this direction, all 24,000 villages of the state are being connected through a network of pipelines. Besides, in order to store surface runoff, the local tanks (ponds) are also being restructured under mission Kakatiya (https://missionkakatiya. cgg.gov.in/). This will provide water for irrigation 


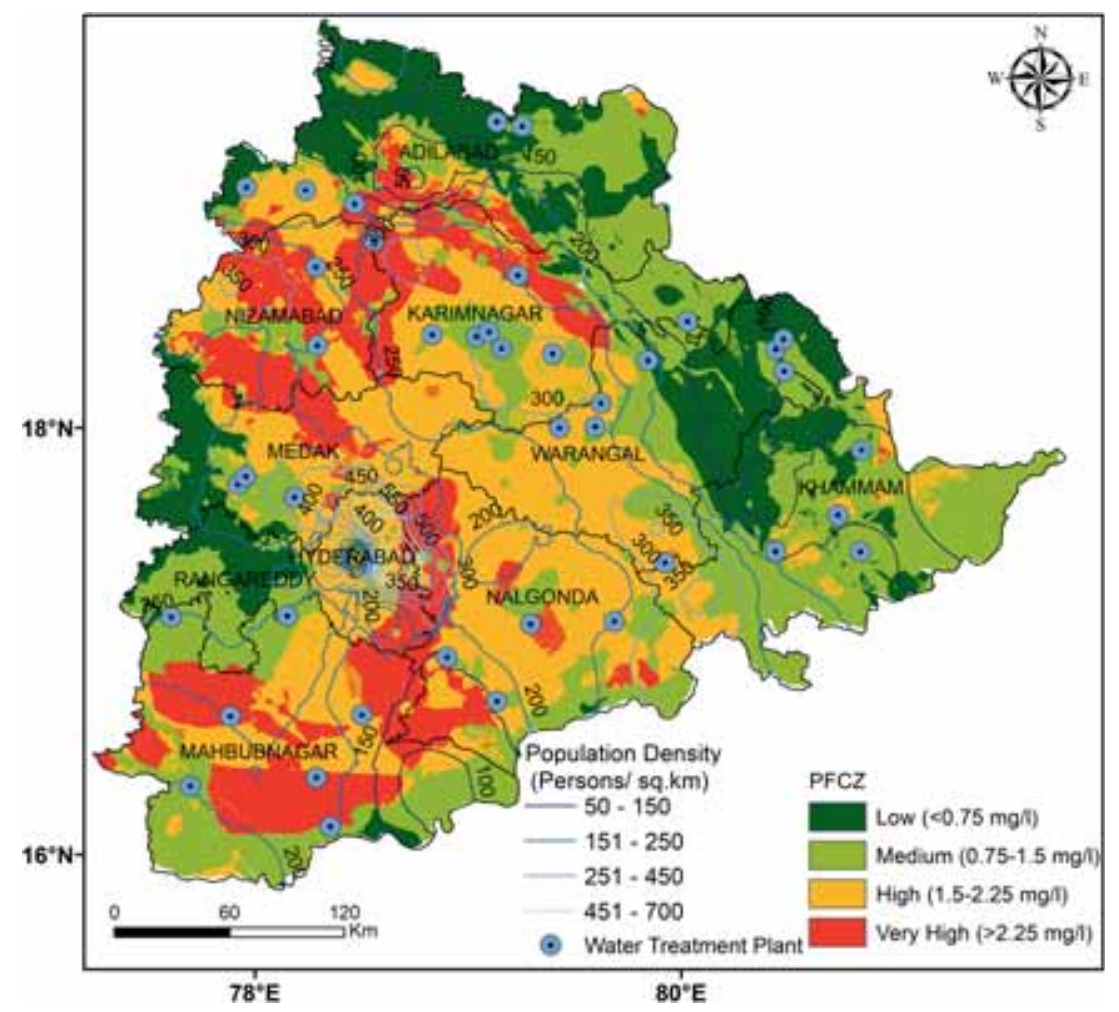

Figure 7. Distribution of population density and water treatment plants across Telangana. The PFC zone map in the background helps in understanding the extent of population which may be exposed to contaminated water.

and will also help in improving the groundwater recharge, which may eventually dilute the fluoride concentration in the groundwater.

Agriculture is one of the major occupations of the rural communities in the state and out of 11.5 million hectares of land, about $43 \%$ of it is tagged under net cropped area. However, only $46 \%$ (2.29 million hectares) land under the cropped area category have surface irrigation facilities and the rest of the land depends on groundwater sources for irrigation. It means that a significant proportion of agricultural land is also being irrigated using fluoride contaminated water, mostly through bore wells. During the year 2006-2007, about 1.3 million (excluding Hyderabad district) dug and tube wells were supplying water for irrigation purposes (TS SYB 2017). Therefore, a larger strategy is needed to reduce the dependence of groundwater for irrigation and also to educate locals about the risk of using locally grown agriculture produce irrigated by fluoride-contaminated water. Improving the groundwater recharge by the identification of artificial recharge sites across the PFC zones could also help, particularly in severely affected regions.

\section{Conclusions}

Applications of RS-driven data and GIS-based AHP and overlay techniques prove to be a useful combination for providing a PFC zone. The main strength of the map of provided PFC zones is that it integrates the regional scale thematic maps of numerous environmental variables validated through a large database of fluoride measurements from different parts of the state. The main weakness of this model lies in the lack of detailed information on a regional scale, particularly for mineralogical composition and the uneven distribution of reported fluoride points. More specific mineralogical composition data pertaining to fluoride-bearing minerals would facilitate the characterisation of the fluoride source and enrichment process. In spite of these limitations, this study is the first such attempt to offer a regional scale potential contamination zone for an entire state. The output map offers a firsthand insight into the severity of fluoride contamination in Telangana for researchers, administrators and planners. It is particularly important to choose the areas on a priority basis for supplying drinking water 
under state-sponsored programmes such as Mission Bhagiratha and restore ponds under Mission Kakatiya. This map of PFC zones will also provide the basis for the identification of suitable artificial recharge sites in highly contaminated zones to dilute the fluoride in groundwater.

\section{Acknowledgements}

KKR is grateful to the DST-Inspire Fellowship Program, India, for providing financial support (IF150795). HG thanks UGC for the faculty position under the Faculty Recharge Programme. The authors would also like to thank the director, CSIR-National Geophysical Research Institute. The accessible database online on the portals of Central Ground Water Board, Survey of India, NRSC-Bhuvan, Geological Survey of India and WRIS India, were greatly helpful in carrying out this study. We are grateful to AE Subimal Ghosh and the anonymous reviewers for their thoughtful reviews and comments on the original manuscript.

\section{References}

Amini M, Mueller K, Abbaspour K C, Rosenberg T, Afyuni $\mathrm{M}$ and Møller K N et al. 2008 Statistical modeling of global geogenic fluoride contamination in groundwaters; Environ. Sci. Technol. 42(10) 3662-3668.

Arveti N, Sarma M, Aitkenhead-Peterson J and Sunil K 2011 Fluoride incidence in groundwater: A case study from Talupula, Andhra Pradesh, India; Environ. Monit. Assess. 172(1-4) 427-443.

Ayoob S and Gupta A K 2006 Fluoride in drinking water: A review on the status and stress effects; Crit. Rev. Env. Sci. Technol. 36(6) 433-487.

Babiker I S, Mohamed M A, Hiyama T and Kato K 2005 A GIS-based DRASTIC model for assessing aquifer vulnerability in Kakamigahara Heights, Gifu Prefecture, central Japan; Sci. Total Environ. 345(1) 127-140.

BIS 2012 Bureau of Indian Standards; IS 10500:2012 Manak Bhawan, New Delhi, India.

Brindha K, Rajesh R, Murugan R and Elango L 2011 Fluoride contamination in groundwater in parts of Nalgonda District, Andhra Pradesh, India; Environ. Monit. Assess. 172(1) 481-492.

Brindha K, Jagadeshan G, Kalpana L and Elango L 2016 Fluoride in weathered rock aquifers of southern India: Managed aquifer recharge for mitigation; Environ. Sci. Pol. Res. 23(9) 8302-8316.

Census 2011 Census Report-2011; Office of the Registrar General \& Census Commissioner, India.

CGWB 2015 Ground water year book - 2014-2015; Telangana State.
CGWB-Annual 2015 Central Ground Water Board - annual report, India 2014-2015.

Chakraborti D, Rahman M M, Chatterjee A, Das D, Das B and Nayak B et al. 2016 Fate of over 480 million inhabitants living in arsenic and fluoride endemic Indian districts: Magnitude, health, socio-economic effects and mitigation approaches; J. Trace Elem. Med. Biol. 38 3345.

Chitsazan M and Akhtari Y 2009 A GIS-based DRASTIC model for assessing aquifer vulnerability in Kherran Plain, Khuzestan, Iran; Water Resour. Manag. 23(6) 11371155 .

Foody G M 2002 Status of land cover classification accuracy assessment; Remote Sens. Environ. 80(1) 185-201.

Foody G M 2008 Harshness in image classification accuracy assessment; Int. J. Remote Sens. 29(11) 3137-3158.

Gautam R, Bhardwaj N and Saini Y 2010 Fluoride accumulation by vegetables and crops grown in Nawa Tehsil of Nagaur district (Rajasthan, India); J. Phytopathol. 2(2) 80-85.

GSI 1993 Geological map of India, published by Geological Survey of India.

Handa B 1975 Geochemistry and genesis of fluoridecontaining ground waters in India; Groundwater 13(3) $275-281$.

Jacks G, Bhattacharya P, Chaudhary V and Singh K 2005 Controls on the genesis of some high-fluoride groundwaters in India; Appl. Geochem. 20(2) 221-228.

Karthikeyan G, Pius A and Apparao B 1996 Contribution of fluoride in water and food to the prevalence of fluorosis in areas of Tamil Nadu in south India; Fluoride 29(3) 151-155.

Kumar V V, Sai C, Rao P and Rao C 1991 Studies on the distribution of fluoride in drinking water sources in Medchal Block, Ranga Reddy District, Andhra Pradesh, India; J. Fluorine Chem. 55(3) 229-236.

Lerner D N and Harris B 2009 The relationship between land use and groundwater resources and quality; Land Use Policy (S26) S265-S273.

Machender G, Dhakate R and Reddy M N 2014 Hydrochemistry of groundwater (GW) and surface water (SW) for assessment of fluoride in Chinnaeru river basin, Nalgonda district, (AP) India; Environ. Earth Sci. 72(10) 4017 4034 .

Machiwal D, Jha M K and Mal B C 2011 Assessment of groundwater potential in a semi-arid region of India using remote sensing, GIS and MCDM techniques; Water Resour. Manag. 25(5) 1359-1386.

Mall R K, Gupta A, Singh R, Singh R S and Rathore L S 2006 Water resources and climate change: An Indian perspective; Curr. Sci. 90(12) 1610-1626.

Mollert I 1993 Endemic dental fluorosis (oral diseases in the tropics); Oxford University Press, Delhi.

Mondal N C, Prasad R K, Saxena V K, Singh Y and Singh V S 2009 Appraisal of highly fluoride zones in groundwater of Kurmapalli watershed, Nalgonda district, Andhra Pradesh (India); Environ. Earth Sci. 59(1) 63-73.

Mukherjee I and Singh U K 2018 Groundwater fluoride contamination, probable release, and containment mechanisms: A review on Indian context; Environ. Geochem. Health 40(6) 2259-2301. 
Narsimha A and Sudarshan V 2016 Assessment of fluoride contamination in groundwater from Basara, Adilabad District, Telangana State, India; Appl. Water Sci., https://doi.org/10.1007/s13201-016-0489-x.

Narsimha A and Sudarshan V 2017 Contamination of fluoride in groundwater and its effect on human health: A case study in hard rock aquifers of Siddipet, Telangana State, India; Appl. Water Sci. 7(5) 25012512 .

Nawlakhe W G, Kulkarni D N, Pathak B N and Bulusu K R 1975 Defluoridation of water by Nalgonda technique; Ind. J. Environ. Health 17 26-65.

NSSO 2006 Morbidity, health care and the condition of the aged, national sample survey; 60th Round (JanuaryJune 2004), Report N0507, Ministry of Statistics and Programme Implementation, Government of India, New Delhi.

Pathak D R, Hiratsuka A, Awata I and Chen L 2009 Groundwater vulnerability assessment in shallow aquifer of Kathmandu valley using GIS-based DRASTIC model; Environ. Geol. 57(7) 1569-1578.

Planning Commission 2002 Government of India, Vol. 104, New Delhi.

Radhakrishna B 1987 Geology and mineral resources of Andhra Pradesh; Geol. Soc. India 29(5) 531.

Radhika V and Praveen G 2012 Determination of fluoride status in groundwater of Kommala area of district Warangal (Andhra Pradesh, India): A case study; Adv. Appl. Sci. Res. 3(4) 2523-2528.

Rahman A 2008 A GIS based DRASTIC model for assessing groundwater vulnerability in shallow aquifer in Aligarh, India; Appl. Geogr. 28(1) 32-53.

Ramesam V and Rajagopalan K 1985 Fluoride ingestion into the natural waters of hard-rock areas, Peninsular India; Geol. Soc. India 26(2) 125-132.

Rao N S 2006 Seasonal variation of groundwater quality in a part of Guntur District, Andhra Pradesh, India; Environ. Geol. 49(3) 413-429.

Rao N S 2009 Fluoride in groundwater, Varaha River Basin, Visakhapatnam District, Andhra Pradesh, India; Environ. Monit. Assess. 152(1) 47-60.

Rao N S and Devadas D J 2003 Fluoride incidence in groundwater in an area of Peninsular India; Environ. Geol. 45(2) $243-251$

Rao N R, Rao N, Rao K S P and Schuiling R 1993 Fluorine distribution in waters of Nalgonda district, Andhra Pradesh, India; Environ. Geol. 21(1-2) 84-89.

Reddy A G, Reddy D V, Rao P N and Prasad K M 2010a Hydrogeochemical characterization of fluoride rich groundwater of Wailpalli watershed, Nalgonda District, Andhra Pradesh, India; Environ. Monit. Assess. 171(14) 561-577.

Reddy D, Nagabhushanam P, Sukhija B, Reddy A and Smedley P 2010b Fluoride dynamics in the granitic aquifer of the Wailapally watershed, Nalgonda District, India; Chem. Geol. 269(3) 278-289.

Saaty T L 1980 The analytic hierarchy process: Planning, priority setting; resource allocation; Vol. 287, MacGrawHill, New York International Book Company.

Saaty T L 1994 How to make a decision: The analytic hierarchy process; Interfaces (Providence) 24(6) 1943.
Saaty T L 2001 The seven pillars of the analytic hierarchy process (Lecture Notes in Economics and Mathematics), pp. $15-37$.

Saaty T L and Kearns K P 2014 Analytical planning: The organization of system, Vol. 7.

Saidi S, Bouri S and Dhia H B 2010 Groundwater vulnerability and risk mapping of the Hajeb-jelma aquifer (central Tunisia) using a GIS-based DRASTIC model; Environ. Earth Sci. 59(7) 1579-1588.

Satyanarayana E, Dhakate R, Kumar D L, Ravindar P and Muralidhar M 2017 Hydrochemical characteristics of groundwater quality with special reference to fluoride concentration in parts of Mulugu-Venkatapur Mandals, Warangal district, Telangana; Geol. Soc. India 89(3) $247-$ 258.

Saxena V and Ahmed S 2003 Inferring the chemical parameters for the dissolution of fluoride in groundwater; Environ. Geol. 43(6) 731-736.

Sener E and Davraz A 2013 Assessment of groundwater vulnerability based on a modified DRASTIC model, GIS and an analytic hierarchy process (AHP) method: The case of Egirdir Lake basin (Isparta, Turkey); Hydrogeol. J. 21(3) 701.

Shaji E, Viju J and Thambi D 2007 High fluoride in groundwater of Palghat District, Kerala; Curr. Sci. 92(2) 240-245.

Shortt H, McRobert G, Barnard T and Mannadi N 1937 Endemic fluorosis in the Madras Presidency; Indian J. Med. Res. 25 553-568.

Sreedevi P, Ahmed S, Madé B, Ledoux E and Gandolfi J-M 2006 Association of hydrogeological factors in temporal variations of fluoride concentration in a crystalline aquifer in India; Environ. Geol. 50(1) 1-11.

Stehman S V, Wickham J, Smith J and Yang L 2003 Thematic accuracy of the 1992 National Land-Cover Data for the eastern United States: Statistical methodology and regional results; Remote Sens. Environ. 86(4) 500516.

Sudarshan V 2015 Geochemistry of fluoride bearing groundwater in parts of Telangana State, India; J. Wat. Res. Hyd. Eng. 4(4) 380-387.

Sujatha D 2003 Fluoride levels in the groundwater of the south-eastern part of RangaReddy district, Andhra Pradesh, India; Environ. Geol. 44(5) 587-591, https:// doi.org/10.1007/s00254-003-0795-0.

Sujatha D and Reddy B R 2003 Quality characterization of groundwater in the south-eastern part of the RangaReddy district, Andhra Pradesh, India; Environ. Geol. 44(5) 579-586.

Susheela A 1999 Fluorosis management programme in India; Curr. Sci. 77(10) 1250-1256.

Teotia S and Teotia M 1984 Endemic fluorosis in India: A challenging national health problem; J. Assoc. Physicians India 32(4) 347.

Thapa R, Gupta S and Reddy D 2017 Application of geospatial modelling technique in delineation of fluoride contamination zones within Dwarka Basin, Birbhum, India; Geosci. Frontiers 8(5) 1105-1114.

TS SYB 2017 Telangana state statistical year book 2017; Directorate of Economics and Statistics, Hyderabad.

Waldbott G L 1963 Fluoride in food; Am. J. Clin. Nutr. 12(6) 455-462. 
World Bank 2010 Deep Wells and Prudence: Towards Pragmatic Action for Addressing Groundwater Overexploitation in India; The World Bank, Washington, DC 97.

World Health Organization 2010 World health statistics 2010; World Health Organization.

http://bhuvan.nrsc.gov.in/gis/thematic/index.php. http://missionbhagiratha.telangana.gov.in/.

http://slusi.dacnet.nic.in/.

http://www.imd.gov.in.

https://earthexplorer.usgs.gov.

https://lta.cr.usgs.gov/SRTM1Arc.

https://missionkakatiya.cgg.gov.in/.

Corresponding editor: Subimal GHosh 